JOURNAL OF SECURITY AND SUSTAINABILITY ISSUES

ISSN 2029-7017 print/ISSN 2029-7025 online

2019 March Volume 8 Number 3

http://doi.org/10.9770/jssi.2019.8.3(7)

Scopus

\title{
ASSESSMENT OF INFORMATION TECHNOLOGIES INFLUENCE ON FINANCIAL SECURITY OF ECONOMY
}

\author{
Volodymyr Tkachenko ${ }^{1}$, Aleksy Kwilinski² ${ }^{2}$ Oleksandr Korystin ${ }^{3}$, Natalia Svyrydiuk ${ }^{4}$, Iryna Tkachenko ${ }^{5}$ \\ ${ }^{1}$ Kyiv National University of Construction and Architecture, 31, Povitroflotsky Avenue, Kyiv, 03680, Ukraine \\ ${ }^{2 *}$ The London Academy of Science and Business, 3rd Floor, 120, Baker Street, London W1U 6TU, England \\ ${ }^{3,4}$ State Research Institute of the Ministry of Internal Affairs of Ukraine,4a, Y. Gutsalo Lane, Kyiv, 01011, Ukraine \\ ${ }^{5}$ Academy of the State Penitentiary Service, 34, Honcha Street, Chernihiv, 14000, Ukraine
}

E-mail: ${ }^{2 *}$ koaduep@gmail.com

Received 11 March 2018; accepted 22 January 2019; published 30 March 2019

\begin{abstract}
The behavior of agents to ensure financial security on the basis of game theory was analyzed, the winning strategy taking into account risk and uncertainty was determined. Using Data Mining the useful functions of this technology were identified to ensure financial security: suspicious transactions determination, credit risks analysis, client account reliability analysis, financial indicators predicting and risks control. A comparison was made of the assessment of the effectiveness of various data mining algorithms on the nature of financial transactions and decision-making procedures in the financial security system. It was proved that the development of information technology has created a whole range of vulnerabilities in the financial system, in particular, has transformed the form of money in modern conditions - the emergence of a cryptocurrency. The influence of the formation and development of cryptocurrency on financial security at all levels of the economy: micro and macro was analyzed.
\end{abstract}

Keywords: financial security, game theory, hawala system, prisoner's dilemma, Data Mining, cryptocurrency, Bitcoin

Reference to this paper should be made as follows: Tkachenko, V.; Kwilinski, A.; Korystin, O.; Svyrydiuk, N. 2019. Assessment of information technologies influence on financial security of economy, Journal of Security and Sustainability Issues 8(3): 375-385.

http://doi.org/10.9770/jssi.2019.8.3(7)

JEL Classifications: F52, O39

\section{Introduction}

Economic security belongs to the fundamental conditions of existence of a country that cares about ensuring the normal life of its people in the environment of international and internal conflicts. Now traditional war has been replaced by various forms of hidden, outwardly civilized, but, in fact, very cynical confrontation, among which the use of an arsenal of financial instruments plays a leading role. And conflicts that have an economic background can develop into specific armed confrontations, called irregular or hybrid wars.

At the same time, we can not effectively analyze and predict the processes of formation of public debt, exchange rate, the financial crisis, and the like with the help of well-known theories. Therefore, in the context of the globalization of the economy and increasing its vulnerability to crisis phenomena, the formation and implementation of the concept of financial security of a country are of paramount importance. 


\section{Literature Survey}

Correct identification of topical security issues is possible only with an adequate assessment of the real and potential threats to human well-being. It is important both to be in a state of readiness to respond to existing threats and not to create systems to respond to non-existent threats (Tvaronavičienė, M. (2018); Mikhaylov, A. S.; Mikhaylova, A. A.; Savchina, O. V. (2018); Mamedov, O.; Tumanyan, Y.; Ishchenko-Padukova, O. \& Movchan, I. (2018)) .A significant part of the threats is caused by the conflict of interests of various members of society (Chen, K. C., Cheng, Q., Lin, Y. C., Lin, Y. C., \& Xiao, X. (2016)).

The management of economic systems in conflict-free situations and in situations of acute conflicts should be significantly different. The theory of financial management in conflict-free situations is currently quite well developed, although it has some debatable moments. We are talking about such areas of financial science as financial management, budget management, tax management, etc. (Sun, W., \& Xu, Y. (2016); Osipov, G. V.; Glotov, V. I. \& Karepova, S. G. (2018); Vandina, O.; Mkrtychan, Z.; Denisov, I.; Vechkinzova, Y. (2018)).

Managers, armed only with knowledge, which have a positive effect in conflict-free, non-crisis conditions, tend to act in critical situations, proceeding from the patterns known to them. Such a course of conduct naturally leads to financial losses or even to the liquidation of a business unit through bankruptcy (Chemla, Y., \& Richard, C. (2017)). It is important to realize that the overall objectives of a business unit remain the same, both in conflict-free and conflict situations.

However, the main factors of achievement and obstacles to the realization of goals, depending on the situation, may differ significantly. Problems of financial security outside the sphere of relations between different people simply do not exist (Lyons, A. C., Grable, J. E., \& Joo, S. H. (2018)). However, subjectively determined threats have two main forms of manifestation: violence (physical impact) and deception (information impact). Financial threats often manifest themselves as attempts by some people to appropriate or destroy the resources of others through actions that are provided in a kind of legal and (or) economically sound financial transaction. The financial danger is characterized by the fact that the conflict is disguised as cooperation, while the exploitation is presented as a fair distribution of resources (Singh, S., \& Singh, N. (2016, December). Therefore, financial security is the result of a proper response to those threats to financial sustainability, primarily related to deception and disinformation.

According to the game theory, if players can evaluate the possibility of betrayal by others, experience influences their behavior. According to statistics, inexperienced players are usually too peaceful or aggressive (Scharpf, F. W. (2018)). If they act like this forever, they will lose because of unnecessary aggressiveness or altruism. Getting more experience, they realistically estimate the likelihood of betrayal and achieve the best results (Tetiana, H., Karpenko, L., Fedoruk, O., Shevchenko, I., \& Drobyazko, S. (2018)). Early frauds have a greater effect on inexperienced players than later ones on experienced ones. This explains the significant role of early experience for young people and their particular vulnerability to unmotivated aggression, after which they sometimes become too aggressive themselves. Collaboration in early games, strengthening confidence, reduces the likelihood of betrayal in the group. Self-sacrifice may in some situations strengthen the morale of the group. If the group is small, positive behavior is more likely to reciprocate, which encourages participants to further cooperation. At the same time, a good attitude without a cause is an indulgence that can impair moral qualities. These processes contribute to the study of mutual altruism, group and family selection and ethics.

\section{Methods}

Among the many regularities identified by mathematical modeling of economic situations, from the standpoint of financial security, there are three the most interesting (Aumann, R. J. (2017)). Firstly, with a long-term confrontation (multiple interaction) of more than two participants, a compromise turns out to be a profitable strategy. The participant of the game, who received benefits due to the deception of opponents in a single interaction, loses in further interactions, at least, loses what he received at the beginning of the game. Secondly, 
even if the parties do not enter into communication (non-cooperative game), their behavior is mutually agreed, that is, even opponents uneven in resources depend on each other to a greater extent, the more their expenses for managing conflict actions. Thirdly, in case of conflict interaction, the largest share of resources produced by two parties is received by the one that produces less and spends more on conflict redistribution. But, having won, it gets less than it could get from cooperation, since the cost of managing the conflict reduces the productivity and competitiveness of all parties and the total amount of available goods.

The need for a hierarchical construction of a system for studying financial security problems is due to the complexity of processing and using large amounts of information with limited time resources. It is necessary to determine the priority objects or subjects of the financial security formation, approaches to its study, research methods, public regulatory institutions and indicators of the level of financial security. Taking into account the existing theoretical developments and actual problems of practice, we offer a scheme for choosing the priorities of the relevant study (Tetiana, H., Chorna M., Karpenko L., Milyavskiy M. \& Drobyazko S. (2018)).

\section{Results}

Turning to the theory of games, it is worth noting that the optimal decision of the player depends on his opinion on the possible actions of others. Therefore, to develop concepts, the result must be studied how individual players make decisions, not knowing what other players do. A repeated game is defined as a game in which a group of participants expects to interact with each other many times under similar circumstances. Such a situation is modeled with the help of the mathematical apparatus of the "prisoners' dilemma", which can be limitedly or unlimitedly repeated. A limited number of repetitions would make cooperation impossible, because players are not sure about the payouts or possible actions of others. As for the prisoners' repeated dilemma, the Tit-for-Tat (TFT) policy - to be "good" at the initial interaction with an unknown person with whom you expect to have regular future relationships, and then simply repeat the steps of other players - in many cases it may be the best long-term strategy. This showed that mutual altruism, from which others gain an advantage, provided that the operation continues for an indefinite or unknown period of time and that the rate in the game is rather low, is a stable solution to the prisoner's dilemma. The TFT strategy will be profitable if individuals hope to often cooperate in the future.

The Matrix (Table 1) illustrates a one-time game in the prisoner's dilemma.

Table 1. Payout matrix for prisoner's dilemma

\begin{tabular}{|c|c|c|}
\hline & C & D \\
\hline C & $(1,1)$ & $(b, a)$ \\
\hline D & $(a, b)$ & $(0,0)$ \\
\hline
\end{tabular}

Players 1 and 2 can choose between cooperation (C) or deception (D). If both choose to cheat, the win will be 0 for each. If they decide to cooperate, the gain will be 1 for each. It is also possible that one of the players chooses cooperation, while the other - deception. In such a situation, the player who cheats takes a better position than the player who cooperates. Namely: $\mathrm{a}>1, \mathrm{~b}<0$, provided that $\mathrm{a}+\mathrm{b}<2$. In this one-time prisoner problem, there is only one equilibrium point, which is achieved when both players cheat. This is the most stable strategy, since none of the players wants to experience a complete collapse from the fact that his/her actions can be foreseen.

The rational actor $\mathrm{R}$ is the player who chooses the best possible strategy to response, while the mechanical TFT actor is the player who uses a certain strategy that is not necessarily the best. The fact that the player's $\mathrm{R}$ opponent is a TFT player creates strong incentives for player R to cooperate, since consistent cooperation on the part of $\mathrm{R}$ results in a gain of 1 per round for each player. In addition, it is not rational for player $\mathrm{R}$ to cheat in round $t$, and then cooperate in round $t+1$, since this gives him/her a gain of $a+b$ (assuming that TFT cooperated in round $\mathrm{t}$ ). Cooperation will be rational for $\mathrm{R}$ if he/she is convinced that he/she plays with TFT. 
For a player who is deemed to be a TFT, it's better to confirm these expectations. The TFT player chooses cooperation from the start, and then repeats the opponent's actions of the previous round. This is done in order to persuade the opponent to cooperate. The TFT player, by cooperating, has the opportunity to gain a reputation. By this he/she encourages other players to cooperate. In other words, in order to play this game well, you need not to defeat your opponent, but to persuade him/her to cooperate, of course, provided that the players really want the game to end with mutual cooperation. Cooperation can be facilitated in different ways. One of them is punishment for the player if he/she does not cooperate (Nakashydze, L., \& Gil'orme, T. (2015)).

First, let's consider the situation where only one side is uncertain. Two players (hawala agent and customer) play in a repeated prisoner's dilemma. Player 1 (hawala agent) is rational (R) and this is common practice. Player 2 (customer) is also rational, but this is not a common practice, therefore player 2 will be called MR (maybe rational). $\mathrm{R}$ determines the probability $(\mathrm{p})$ that player 2 is rational and the probability $(\mathrm{p}-1)$ that player 2 is a mechanical TFT player.

As shown above, both players can cooperate (C) or deceive (D). This is their initial possible actions (Hilorme, T., Nazarenko Inna, Okulicz-Kozaryn, W., Getman, O. \& Drobyazko, S. (2018)). When players decide to play, they will not have complete information, because, due to the rationality possibility of player 2 , there is uncertainty about the gain. Considering the results and advantages of this game, we can conclude that $a>1>0>b$, but if both players prefer a, it will be difficult to ensure cooperation. Here it seems possible to assume that, apparently, religion or similar cultural characteristics force the players to respect a certain result of the game - 1 for each, when both choose cooperation. The use of the mathematical apparatus shows that if there are optimization costs, TFT types will survive in competition with rational actors, provided that the number of rounds in the prisoner's problem will be large enough. This result is based on the assumption that being rational is expensive, while being TFT does not incur significant expenses. An explanation using a prisoner's dilemma may help to explain why value transfer systems originate from developing countries. With the development and complexity of the economy, the motivation for using hawala-like systems may decrease. However, this is only one side of the theory. Some informal cost transferring systems have proven to work despite economic development. Another IVTS feature is their high ability to adapt to changes, such as economic crises, unrest and war.

Despite its informal nature, the hawala system has direct and indirect consequences in the macroeconomic sphere due to financial and tax factors. One such consequence is the potential impact of hawala on the monetary accounts of the countries of both parties to the transaction. Since these transactions are not reflected in official statistics, the transfer of funds from one country to another is not counted as an increase in the foreign assets of the recipient country or as an increase in the obligations of the sending country. As a result, money changes the owner, and the official indicator of the money supply remains unchanged. However, transactions within hawala may affect the composition of the money supply in the recipient country. In the field of money transfers, such transactions are usually carried out with cash, although hawaladars can also use the banking system. Persons from developing countries that transfer money abroad through the hawala system for investment or other purposes usually belong to wealthy groups. They provide local hawaladars with cash by withdrawing money from their bank account. As a result, transactions in the hawala system, as a rule, increase the amount of cash in circulation. In addition, the system of illegal transfers causes fiscal implications, because the transactions through hawala is not taxed. Negative impact on budget revenues has both illegal and legitimate activities, if this activity involves the participation of the hawala system. There are estimates that around 5,000 hawala brokerage points are operating in the world (Sherraden, M. S., \& Ansong, D. (2016)).

Since we live in the era of information, it is difficult to overestimate the importance of data that is regularly collected in the management of production, in banking, in solving scientific tasks. Powerful computer systems that manage huge databases have become an essential attribute of life for large corporations and even small companies. However, the availability of data alone is still insufficient to improve performance. You need to be able to transform "raw data" into useful information for making important decisions. This is the main purpose of data mining technology - electronic data intelligence. 
Data mining is a modern concept for analyzing data that may at first be inaccurate, heterogeneous, contain gaps, and also have huge volumes. The need for regular analysis of such data has arisen as a result of the spread of information technologies that allow for a detailed logging of the processes of production, trade and finance (Sriramoju, S. B. (2017)). Literally, data mining translates as mining or digging data. An alternative term, quite common, is data intelligence.

In fact, in terms of the composition of the tasks, data mining practically does not differ from the standard set of tools that have been used for more than half a century in the field of statistical data analysis, the search for patterns and training based on precedents. The main difference lies in the efficiency of the algorithms and the technological effectiveness of their use. The overwhelming majority of classical procedures have a quadratic or even cubic, depending on the number of objects, execution time. When the number of objects that exceeds several tens of thousands, they work unacceptably long even on the most modern computers. Specialized data mining algorithms are capable of performing the same tasks in linear or even logarithmic time without significant loss of accuracy. Finding hidden patterns in the data, relationships between different variables, modeling and studying complex systems based on the history of their behavior - these are the subject and tasks of data mining. Data mining results - empirical models, classification rules, clusters discovered, etc. (Ristoski, P., \& Paulheim, H. (2016)).

They can then be integrated into existing decision support systems and used to predict future situations.

From the point of view of financial security, such data mining functions are useful: suspicious transactions determination, credit risks analysis, client account reliability analysis, financial indicators predicting and risks control. Currently, most of the world's leading software manufacturers offer their products and solutions in the field of data mining. As a rule, these are systems in which various mathematical algorithms for data analysis were implemented. They have an advanced graphical interface, rich visualization and manipulation of data, provide access to various data sources, and the like. The following groups of data mining systems can be distinguished. The need for automated data mining has become particularly apparent through vast arrays of historical and new information.

It is difficult to even approximately estimate the amount of daily data accumulated by various companies, government and scientific organizations. Another reason for the growing popularity of data mining is the objectivity of the results obtained. A person-analyst, in contrast to the machine, possess always an inherent subjectivism. A person, to one degree or another, is a hostage of ideas that have already taken shape. Sometimes it is useful, but often causes great harm. And finally, data mining is cheaper. It turns out that it is more profitable to invest money in a data mining solution than to constantly retain a significant staff of highly qualified and expensive professional statisticians. Data mining does not completely exclude the role of man, but considerably simplifies the process of finding knowledge, making it accessible to a wide range of analysts who are not experts in statistics, mathematics, or programming (Apps, E., \& Ono, K. (2017)).

Subject-oriented analytical systems. These systems solve a narrow class of specialized tasks.

Statistical packages. These are powerful mathematical systems designed for the statistical processing of data of any nature. They include numerous statistical analysis tools and have developed graphic tools.

Neural network packets. This is a wide class of various systems that are hierarchical network structures, at the nodes of which there are so-called neurons. Networks are trained by examples and, in many cases, give good prediction results. The main disadvantage of neural networks is the difficulty of interpreting the results. A trained neural network is a black box which work is impossible to understand and control.

Packages that implement the decision tree algorithms. This method is used only for solving classification problems. This is its serious limitation. The result of the method is a hierarchical tree structure of classification rules of the type "If ... Then ...". The advantage of the method is the ability to separate data into a large number of classes. 
Evolutionary programming. This is an approach in which several genetic lines of programs are formed in the system that compete with each other in the accuracy of expression of the dependence studied. Rating systems based on similar cases. These systems find among the past situations close analogues of the current one and choose the course of action that was right for them.

Limited search. These algorithms compute the frequency of combinations of simple logical events in data classes.

Currently, there are conflicting estimates of the effectiveness of various data mining algorithms. In general, it can be argued that the success of various studies and the quality of the decisions made will depend on the correctness of combining the functions of a computer and a person. An expert armed with the means of fast processing of information will ultimately get better results than a specialist relies only on his own intelligence.

\section{Discussion}

Not only computer technology changes modern information and analytical processes in the field of economics and finance. For example, American economists have developed a criterion for estimating from space the economic growth of countries in the absence or incompleteness of official statistics (Buczak, A. L., \& Guven, E. (2016)). Researchers chose the intensity of the night illumination of cities as the measure of progress or regression of the country. According to the authors of this method, it is the evening consumption of goods and services that requires artificial lighting. And the more goods and services available to citizens are, the greater is its GDP.

For example, using the prisoner's dilemma, which is repetitive, we can model pricing policies in oligopolistic markets. Usually, oligopolists cooperate with each other to avoid losses from the "price war".

A similar dilemma situation occurs when two competing organizations decide on advertising costs. The effectiveness of the advertising campaign of each organization decreases with increasing advertising costs from a competitor. If both organizations decide at the same time to increase advertising costs, their market shares and, possibly, revenues remain unchanged, while profits decline. From rational positions, the limit of the size of advertising budgets is the amount of profit, determined without taking into account advertising expenses. However, organizations may work at a loss for some time in order to weaken a competitor. They can also make an agreement to reduce advertising costs. But the incentive to break it always exists.

At the same time, information technologies can change not only the nature of financial transactions and decisionmaking procedures. A number of technologies have significantly transformed the form of money in modern conditions. For most of history, mankind has used monetary systems based on commodity money. Paper money appeared about 1000 years ago and dominates today. Cryptocurrency is a new, experimental type of money that operates in a distributed and decentralized system of secure exchange and transfer of digital banknotes based on cryptography (Li, X., \& Wang, C. A. (2017)). Banknotes of such a system can be exchanged for paper money at the market rate. The first cryptocurrency was Bitcoin, the operation of which began in January 2009. Later, with the use of Bitcoin innovations was created a number of other cryptocurrency. However, some specific parameters of the algorithms laid in their work differed from Bitcoin.

In the first Bitcoin reports, considerable attention was paid to the active use of this system by the online black market site, the Silk Road website. In such a way the erroneous assumption about the anonymity of transactions in the Bitcoin system was spread. In the system there is a public register of all transactions carried out in its history. Although the real names of participants are not included in transactions in the blockchain, Bitcoin addresses are user aliases.

If a bitcoin address is identified in a certain way with a specific individual, then all transactions in the block chain using this address can be easily linked with this individual. Although the transactions in Bitcoin are not completely anonymous, the very presence of a cryptocurrency significantly changes the nature of law 
enforcement to restrict illegal transactions. In the course of operations with traditional money, electronic payments are made through financial intermediaries; therefore, the country, by regulating their work, can limit certain operations. In the Bitcoin system, penalties for illegal transactions may take place later, but they cannot be limited in advance by adjusting the actions of the intermediary. This can seriously affect lawmaking and law enforcement in the area of financial regulation.

In addition, the emergence of a cryptocurrency provides a new meaning to the problem of exchange rate uncertainty. Since Bitcoin is not secured by any assets, the value of this currency depends solely on its usefulness as a means of exchange (Delmolino, K., Arnett, M., Kosba, A., Miller, A., \& Shi, E. (2016, February)). Most likely, bitcoins will always be inherent in the volatility of the course more than paper money, because there is no central bank in their system of operation, and the bitcoin money supply does not respond to changes in demand. According to the "businessviews.com.ua" site, bitcoins are the limited currency for their emission, and the maximum possible amount of emitted bitcoins is 21,000,000. As of May 30, 2017, it issued about $76 \%$ of amount (https://coinmarketcap.com.). When the total currency base of the system reaches $21,000,000$, then any type of emission will be completely stopped (to avoid inflation), after which the system will enter the third final phase - stabilization.

The formation of a cryptocurrency rate depends on demand, so the cost of Bitcoin is not stable (Figure 1).

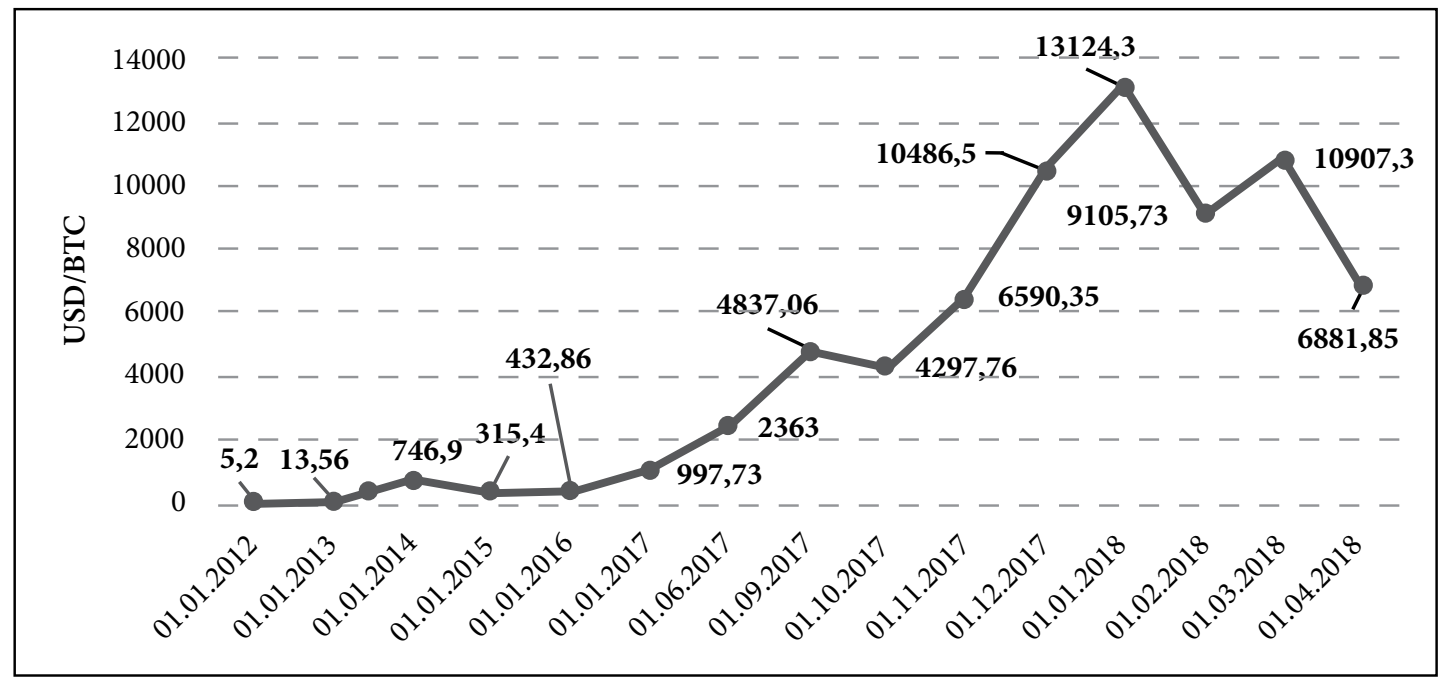

Figure 1. Dynamics of the dollar rate to bitcoin 2012-2018

Source: developed by the author according to the source https://coinmarketcap.com

Analyzing this diagram, we can say that in recent years, the rate fluctuations occur very sharply. Compared to 2012, the bitcoin course increased from USD 5.2 in 2018 to USD 6881.85 per bitcoin. As a result, the cost of the cryptocurrency exceeded the cost of an ounce of gold (1339.3 USD as of 02.2018). The main reason for this was the growth of speculative interest in this digital currency. It should be noted one feature that has been observed in recent years. After an unplanned drop in quotations, there is another jump in the Bitcoin rate and it not only reaches the point from which the next recession began, but improves the former indicator of the value of the cryptocurrency and it beats its own new record. Therefore, those who were able to buy on time and sell this cryptocurrency on time could make a lot of money from small amounts.

On January 16, 2018 the cryptocurrency market (including Bitcoin by 30\%) collapsed. The price of Bitcoin fell to 10 thousand dollars (and on December 17, 2017 it reached about 20 thousand dollars). Of the top 100 currencies, 99 fell by an average of $20 \%$ (Hayes, A. S. (2017)). Such a sharp fluctuation of the rate is associated either with a ban on cryptocurrency exchanges or with a future ban on withdrawal of cryptocurrency into ordinary money. However, cryptocurrency is not limited to one Bitcoin, which is the most popular in the world, and offers the most developed network infrastructure (Table 2). 
Table 2. Capitalization and the rate of the top 10 cryptocurrencies on September 20, 2018

\begin{tabular}{|c|c|c|c|c|}
\hline $\begin{array}{c}\text { Item } \\
\text { № }\end{array}$ & Cryptocurrency name & Price, USD & Price, BTC & Market capitalization, USD \\
\hline 1 & Bitcoin,BTC & 8496.19 & 1 & $143,844,203,115$ \\
\hline 2 & Ethereum, ETH & 584.2 & 0.069 & $57,851,642,770$ \\
\hline 3 & Ripple, XRP & 0.858 & 0.0001 & $33,601,434,036$ \\
\hline 4 & Bitcoin Cash, BCH & 1058.17 & 0.125 & $18,077,855,642$ \\
\hline 5 & Litecoin, LTC & 149.55 & 0.0177 & $8,400,042,028$ \\
\hline 6 & EOS, EOS & 9.85 & 0.0012 & $7,925,277,827$ \\
\hline 7 & Cardano, ADA & 0.285 & 0.00003 & $7,406,456,605$ \\
\hline 8 & Stellar, XLM & 0.369 & 0.00004 & $6,869,296,477$ \\
\hline 9 & IOTA, MIOTA & 1.93 & 0.00022 & $5,353,069,576$ \\
\hline 10 & NEO, NEO & 75.10 & 0.0088 & $4,881,721,000$ \\
\hline
\end{tabular}

Source: developed by the author according to the source https://coinmarketcap.com

The market capitalization of Bitcoin as of September 20, 2018 is $38.56 \%$ of the total market capitalization, the second in terms of capitalization is the cryptocurrency Ethereum - $15.53 \%$, and the third is Ripple, which is 9.10\%. The total market capitalization is USD 373,008,072,802. (https://coinmarketcap.com).

Statistics have shown that investors, technophiles and gamers have the biggest interest in Bitcoin, and travelers have the least interest (Fry, J., \& Cheah, E. T. (2016)).

\section{Conclusions}

The global transition to the information age has changed the era of industrialism, which is ambiguous in its consequences and contains a pronounced crisis component. Therefore, it cannot be viewed unambiguously as a transition to a more prosperous state of society. Modern society has no other set of possible ways of its development, except for those that are caused by the rapid and irreversible development of the newest information technologies with the corresponding transformation of the main areas of human activity, such as economics, politics and culture. The global and informational nature of changes is manifested in the creation of a unified communicative space. In the socio-economic sphere, it is expressed in the construction of a network or information society.

In the context of globalization, the mutual influence of traditional societies with their archaic mechanisms of socio-economic relations and societies that have switched to the post-industrial stage of development occurs. An example of the penetration of archaic financial and credit mechanisms of the era of the emergence of world trade into the modern economic system is the international system of illegal money transfers called hawala.

In the international arena, the cryptocurrency has supporters and those who are neutral towards it. Some consider it a development of the technological process and the "currency of the future", others react negatively to such innovations. Given the endurance of the digital currency and the steady growth in popularity in the global financial arena, some countries are considering the issue of its control and regulation, while others do not recognize the legal status of a cryptocurrency.

Characterized by a high level of complexity, modern information technologies impose extremely high demands on the quality of the corresponding developments. However, in practice, even in developed countries, they do not always achieve an adequate level of quality in this area. And the results of mistakes can be expressed in very significant amounts of money. Given this, the development of information technology has created a whole range of financial system vulnerabilities. 


\section{References}

Apps, E., \& Ono, K. (2017). U.S. Patent No. 9,798,781. Washington, DC: U.S. Patent and Trademark Office. URL: https://patents. google.com/patent/US9798781B2/en

Aumann, R. J. (2017). Game theory. The New Palgrave Dictionary of Economics, 1-40. URL: https://link.springer.com/referencework entry/10.1057\%2F978-1-349-95121-5_942-2

Buczak, A. L., \& Guven, E. (2016). A survey of data mining and machine learning methods for cyber security intrusion detection. IEEE Communications Surveys \& Tutorials, 18(2), 1153-1176. URL: https://ieeexplore.ieee.org/abstract/document/7307098

Chemla, Y., \& Richard, C. (2017). U.S. Patent No. 9,728,028. Washington, DC: U.S. Patent and Trademark Office. URL: https://patents. google.com/patent/US9728028B2/en

Chen, K. C., Cheng, Q., Lin, Y. C., Lin, Y. C., \& Xiao, X. (2016). Financial reporting quality of Chinese reverse merger firms: The reverse merger effect or the weak country effect? The Accounting Review, 91(5), 1363-1390. URL: http://www.aaajournals.org/doi/ abs/10.2308/accr-51376

Delmolino, K., Arnett, M., Kosba, A., Miller, A., \& Shi, E. (2016, February). Step by step towards creating a safe smart contract: Lessons and insights from a cryptocurrency lab. In International Conference on Financial Cryptography and Data Security (pp. 79-94). Springer, Berlin, Heidelberg. URL: https://link.springer.com/chapter/10.1007/978-3-662-53357-4_6

Grinko, A., Bochulia, T., Hrynko, P., Yasinetska, I., \& Levchenko, Ia. (2017). Forming concept of intellectualization information provision of managing an enterprise. Eastern-European Journal of Enterprise Technologies, 5/3(89), 4-14. https://doi.org/10.15587/17294061.2017.111859

Fry, J., \& Cheah, E. T. (2016). Negative bubbles and shocks in cryptocurrency markets. International Review of Financial Analysis, 47, 343-352. URL: https://www.sciencedirect.com/science/article/pii/S1057521916300163

Hayes, A. S. (2017). Cryptocurrency value formation: An empirical study leading to a cost of production model for valuing bitcoin. Telematics and Informatics, 34(7), 1308-1321.URL: https://www.sciencedirect.com/science/article/abs/pii/S0736585315301118

Hilorme, T., Nazarenko Inna, Okulicz-Kozaryn, W., Getman, O. \& Drobyazko, S. (2018). Innovative model of economic behavior of agents in the sphere of energy conservation. Academy of Entrepreneurship Journal, Volume 24, Issue 3, 2018. URL: https://www. abacademies.org/journals/month-september-year-2018-vol-24-issue-3-journal-aej-past-issue.html

Karpenko, L., Serbov, M., Kwilinski, A., Makedon, V., \& Drobyazko, S. (2018). Methodological platform of the control mechanism with the energy saving technologies. Academy of Strategic Management Journal 17(5): 1939-6104-17-5-271: 1-7. Retrieved from https://www.abacademies.org/articles/Methodological-platform-of-the-control-mechanism-1939-6104-17-5-271.pdf

Kwilinski, A. (2018). Mechanism of modernization of industrial sphere of industrial enterprise in accordance with requirements of the information economy, Marketing and Management of Innovations, 4, 116-128. http://doi.org/10.21272/mmi.2018.4-11

Kuznyetsova, A., \& Pogorelenko, N. (2018). Assessment of the banking system financial stability based on the differential approach. Banks and Bank Systems, 13(3), 120-133. http://dx.doi.org/10.21511/bbs.13(3).2018.12

Lakhno, V., Malyukov, V., Bochulia, T., Hipters, Z., Kwilinski, A., \& Tomashevska, O. (2018). Model of managing of the procedure of mutual financial investing in information technologies and smart city systems. International Journal of Civil Engineering and Technology, 9(8), 1802-1812. Retrieved from http://www.iaeme.com/MasterAdmin/UploadFolder/IJCIET_09_08_181/IJCIET_09_08_181.pdf

Li, X., \& Wang, C. A. (2017). The technology and economic determinants of cryptocurrency exchange rates: The case of Bitcoin. Decision Support Systems, 95, 49-60. URL: https://www.sciencedirect.com/science/article/pii/S0167923616302111

Lyons, A. C., Grable, J. E., \& Joo, S. H. (2018). A cross-country analysis of population aging and financial security. The Journal of the Economics of Ageing, 12, 96-117. URL: https://www.sciencedirect.com/science/article/pii/S2212828X17300403

Mamedov, O.; Tumanyan, Y.; Ishchenko-Padukova, O.; Movchan, I. 2018. Sustainable economic development and post-economy of artificial intelligence. Entrepreneurship and Sustainability Issues, 6(2), 1028-1040. https://doi.org/10.9770/jesi.2018.6.2(37)

Mikhaylov, A. S.; Mikhaylova, A. A.; Savchina, O. V. (2018). Innovation security of cross-border innovative milieu. Entrepreneurship and Sustainability Issue, 6(2), 754-766. https://doi.org/10.9770/jesi.2018.6.2(19)

Nakashydze, L., \& Gil'orme, T. (2015). Energy security assessment when introducing renewable energy technologies. Eastern-European Journal of Enterprise Technologies, 4/8(76), 54-59. URL: http://nbuv.gov.ua/UJRN/Vejpte_2015_4\%288\%29_10 
Osipov, G. V.; Glotov, V. I.; Karepova, S. G. 2018. Population in the shadow market: petty corruption and unpaid taxes. Entrepreneurship and Sustainability Issues, 6(2), 692-710. https://doi.org/10.9770/jesi.2018.6.2(16)

Ristoski, P., \& Paulheim, H. (2016). Semantic Web in data mining and knowledge discovery: A comprehensive survey. Web semantics: science, services and agents on the World Wide Web, 36, 1-22. URL: https://www.sciencedirect.com/science/article/pii/ S0167923616302111

Scharpf, F. W. (2018). Games real actors play: Actor-centered institutionalism in policy research. Routledge. URL: https://www. taylorfrancis.com/books/9780429968822

Sherraden, M. S., \& Ansong, D. (2016). Financial literacy to financial capability: Building financial stability and security. In International Handbook of Financial Literacy (pp. 83-96). Springer, Singapore. URL: https://link.springer.com/chapter/10.1007/978-981-10-0360-8_7

Singh, S., \& Singh, N. (2016, December). Blockchain: Future of financial and cyber security. In Contemporary Computing and Informatics (IC3I), 2016 2nd International Conference on (pp. 463-467). IEEE. URL: https://ieeexplore.ieee.org/abstract/document/7918009

Sriramoju, S. B. (2017). OPPORTUNITIES AND SECURITY IMPLICATIONS OF BIG DATA MINING. International Journal of ResearchinScienceandEngineering,3(6),44-58.URL:https://www.researchgate.net/profile/Shoban_Sriramoju/publication/321097052 OPPORTUNITIES AND SECURITY IMPLICATIONS OF BIG DATA MINING/1inks/5a0d2c0c4585153829b1a5d0/ OPPORTUNITIES-AND-SECURITY-IMPLICATIONS-OF-BIG-DATA-M̄INING.pdf

Sun, W., \& Xu, Y. (2016). Financial security evaluation of the electric power industry in China based on a back propagation neural network optimized by genetic algorithm. Energy, 101, 366-379. URL: https://www.sciencedirect.com/science/article/abs/pii/ S0360544216300895

Tetiana, H., Chorna M., Karpenko L., Milyavskiy M. \& Drobyazko S. (2018). Innovative model of enterprises personnel incentives evaluation. Academy of Strategic Management Journal. 17(3) URL: https://www.abacademies.org/journals/month-june-year-2018-vol17-issue-3-journal-asmj-past-issue.html

Tetiana, H., Karpenko, L., Fedoruk, O., Shevchenko, I., \& Drobyazko, S. (2018). Innovative methods of performance evaluation of energy efficiency project. Academy of Strategic Management Journal, 17(2), 112-110. URL: https:/www.abacademies.org/articles/ innovative-methods-of-performance-evaluation-of-energy-efficiency-projects-7067.html

Tvaronavičienė M. (2018). Towards internationally tuned approach towards critical infrastructure protection. Journal of Security and Sustainability Issues, 8(2), 143-150. https://doi.org/10.9770/jssi.2018.8.2(2)

Vandina, O.; Mkrtychan, Z.; Denisov, I.; Vechkinzova, Y. (2018). The tax mechanism of managing the process of formation of information economy in modern Russia. Entrepreneurship and Sustainability Issues, 6(2), 830-839. https://doi.org/10.9770/jesi.2018.6.2(24)

\section{Short biographical note about the contributors at the end of the article:}

Volodymyr Tkachenko, Doctor of Science in History, Professor, Vice-Rector, Kyiv National University of Construction and Architecture ORCID ID: orcid.org/0000-0003-2114-7194

Aleksy Kwilinski, Ph.D. in Economics, The London Academy of Science and Business, London, England ORCID ID: orcid.org/0000-0001-6318-4001

Oleksandr Korystin, Doctor of Science in Law, Professor, Deputy Director, State Research Institute of the Ministry of Internal Affairs of Ukraine

ORCID ID: orcid.org/0000-0001-9056-5475

Natalia Svyrydiuk, Doctor of Science in Law, Associate Professor, Deputy Head of Scientific Research Laboratory of Criminological Research, State Research Institute of the Ministry of Internal Affairs of Ukraine

ORCID ID: orcid.org/0000-0001-9772-1119

Iryna Tkachenko, Ph.D. in History, Associate Professor, Professor at the Department of Pedagogy and Humanities, Academy of the State Penitentiary Service, Ukraine

ORCID ID: orcid.org/0000-0001-9068-1054 
Register for an ORCID ID: https://orcid.org/register

This work is licensed under the Creative Commons Attribution International License (CC BY). http://creativecommons.org/licenses/by/4.0/ (c) (i) Open Access 